\section{(1) \\ CrossMark}

\title{
The unmet medical need of pulmonary hypertension in idiopathic pulmonary fibrosis
}

\author{
Vincent Cottin $\mathbb{1}^{1}$, Laura C. Price ${ }^{2}$ and Claudia Valenzuela ${ }^{3}$ \\ Affiliations: ${ }^{1}$ Hospices Civils de Lyon, Coordinating Reference Center for Rare Pulmonary Diseases, Dept of \\ Respiratory Medicine, Louis Pradel Hospital; University Claude Bernard Lyon 1, University of Lyon, UMR 754, \\ Lyon, France. ${ }^{2}$ Royal Brompton Hospital, London, UK. ${ }^{3}$ Hospital La Princesa, Madrid, Spain.
}

Correspondence: Vincent Cottin, National Reference Center for Rare Pulmonary Diseases, Dept of Respiratory Medicine, Louis Pradel Hospital, Batiment A4 pneumologie, 28 avenue Doyen Lepine, F-69677 Lyon Cedex, France. E-mail: vincent.cottinachu-lyon.fr

@ERSpublications

Prospective studies are needed for noninvasive detection of pulmonary hypertension in patients with IPF http://ow.ly/Yydw30hoGqk

Cite this article as: Cottin V, Price LC, Valenzuela C. The unmet medical need of pulmonary hypertension in idiopathic pulmonary fibrosis. Eur Respir J 2018; 51: 1702596 [https://doi.org/10.1183/13993003.025962017].

Pulmonary hypertension $(\mathrm{PH})$ is defined as a mean pulmonary artery pressure (PAP) greater or equal to $25 \mathrm{mmHg}$, and is a frequent complication in patients with idiopathic pulmonary fibrosis (IPF) [1], especially at an advanced stage of the disease, or when emphysema is associated, as in the syndrome of combined pulmonary fibrosis and emphysema [2]. At diagnosis, $8 \%$ to $15 \%$ of patients with IPF may already have precapillary $\mathrm{PH}$ [3], a proportion which rises up to $30 \%$ to $50 \%$ of patients at the time of evaluation for lung transplantation [4-7]. The frequency of $\mathrm{PH}$ further increases with comorbidities such as obstructive sleep apnoea, thromboembolism or cardiac diastolic dysfunction [8]. $\mathrm{PH}$, when present, is associated with dramatic worsening of shortness of breath, greater oxygen requirements, more severe limitation to exercise capacity and increased mortality $[4,8-10]$. PH in IPF (group 3 of the World Health Organization pulmonary hypertension classification [11]) is usually of mild or moderate haemodynamic severity, although $2-10 \%$ of patients have a mean PAP greater than $35-40 \mathrm{mmHg}$ [3-5].

Given the relentless, progressive nature of IPF, despite the impact of antifibrotic drugs on disease course, and the impact of $\mathrm{PH}$ on morbidity and survival, it is not surprising that efforts are being made to detect $\mathrm{PH}$ as early as possible in patients with IPF, and that research is being conducted to treat precapillary $\mathrm{PH}$ when present. Unfortunately, there is no validated screening tool for $\mathrm{PH}$ in the setting of interstitial lung disease. Right heart catheterisation (RHC) is the gold standard for the diagnostic confirmation of PH, used in some studies at the time of diagnosis of IPF [3], but it is not appropriate as a routine screening tool because it is invasive. RHC is currently recommended in patients with lung disease if organ transplantation is considered, if pulmonary arterial hypertension or chronic thromboembolic $\mathrm{PH}$ is suspected, in case of episodes of right heart failure, of inconclusive echocardiographic findings with a high level of suspicion and potential therapeutic implications [12], and in selected cases with suspected diastolic

Received: Dec 132017 | Accepted: Dec 142017

Conflict of interest: V. Cottin has received fees for speaking, participated as member of steering committee, investigator to clinical trials, and serving in advisory boards from Actelion, Bayer, Boehringer Ingelheim, GSK, Intermune, MSD, Novartis and Roche. L.C. Price has received educational grants from Actelion and GSK. C. Valenzuela has received fees for speaking and serving in advisory boards from Boehringer Ingelheim and Roche.

Copyright OERS 2018 
left ventricular dysfunction [8] where certainty of assessment of pulmonary capillary wedge pressure is needed. Echocardiography is the most widely used noninvasive method to assess for $\mathrm{PH}$; however, it has low accuracy in patients with advanced respiratory diseases [7, 13, 14], and possible over- or under-estimation of right ventricular systolic pressure by the systolic tricuspid regurgitation velocity at Doppler [13]. Pulmonary function parameters and novel echocardiography parameters have also been studied as noninvasive predictors of PH in IPF; however, they are not discriminant enough to be used alone $[15,16]$. The combination of multiple echocardiographic signs of right heart dysfunction might increase predictive accuracy. Among other potential tools, the pulmonary artery diameter to ascending aorta diameter ratio (PA/Ao) on chest computed tomography may be useful [14], and is predictive of subsequent mortality [17].

Given the insufficient discrimination ability of the parameters studied alone, several groups have proposed scoring systems or a combination of parameters to screen for $\mathrm{PH}$ in patients with IPF. ZISMAN et al. [6] have created a formula to estimate mean PAP based on pulse oximetry $\left(S_{\mathrm{pO}_{2}}\right)$, percent predicted forced vital capacity (FVC) and percent-predicted diffusing capacity (DLCO). The equation $\mathrm{mPAP}=-11.9+0.272 \times \mathrm{P}_{\mathrm{PO}_{2}}+0.0659 \times\left(100-\mathrm{SpO}_{2}\right)+3.06 \times(\% \mathrm{FVC} / \% D \mathrm{LCO})$ had a sensitivity of $71 \%$ and a specificity of $81 \%$ to predict PH in patients with IPF [6], and a sensitivity of $95 \%$ and a specificity of $58 \%$ in a different cohort [16]. ALKUKHUN et al. [14] found that a combination of worse right ventricular function at echocardiography, higher PA/Ao ratio, and a rightward QRS axis deviation at ECG independently predicted precapillary $\mathrm{PH}$ with a c-index of $0.86(0.76-0.92)$. However, these tools have not been validated in prospective cohorts and may arguably not be easy to use routinely.

In this issue of the European Respiratory Journal, FurukAwA et al. [18] in Japan have revisited this challenge with the aim of providing clinicians with a simple scoring system to predict elevated PAP in IPF. The select a cut-off of mean PAP $\geqslant 21 \mathrm{mmHg}$, which is in the realm of "borderline PH" (mean PAP 21$24 \mathrm{mmHg}$ ) at elevated levels of pressure that are above normal values, but below diagnostic PH criteria. Based on a retrospective single centre cohort of 273 treatment-free patients with IPF who had underwent RHC at initial evaluation, they have used logistic regression to create a screening tool for the prediction of elevated mean PAP at RHC. They have created a simple score based on three variables: DLCO $<50 \%$ of predicted value, $\mathrm{PA} / \mathrm{Ao}$ ratio $\geqslant 0.9$, and $\mathrm{PaO}_{2}<80 \mathrm{mmHg}$. Inter-rater variability for $\mathrm{PA} / \mathrm{Ao}$ ratio $\geqslant 0.9$ was good, with an intraclass correlation coefficient of 0.706 . A score of 3 (with the three criteria present) had a specificity of $95.8 \%$ and a negative predictive value of $85.1 \%$.

TABLE 1 Main randomised controlled clinical trials using drugs approved for pulmonary arterial hypertension (PAH) in idiopathic pulmonary fibrosis (IPF) and IPF associated with pulmonary hypertension (PH)

Drug tested Primary outcome

Result

\section{Trials targeting IPF with drugs approved in $\mathrm{PAH}$ STEP-IPF [22]}

ARTEMIS-IPF [23]

BUILD-1 [24]

BUILD-3 [25]

MUSIC [26]

Trials targeting IPF-PH with drugs approved in PAH ARTEMIS-PH (NCT00879229]

RISE-IIP [27] (results unpublished) BPHIT [28]

\section{Sildenafil}

Ambrisentan

Bosentan

Bosentan

Macitentan FVC

Proportion of patients with $>20 \%$ increase in 6 - $\mathrm{min}$ walk distance

Time to disease progression, defined as death, respiratory hospitalisation, or a categorical decrease in lung function

6-min walk distance

Time to IPF worsening la confirmed decrease from baseline in FVC $\geqslant 10 \%$ and $D \mathrm{LCO} \geqslant 15 \%$, or acute exacerbation of IPF) or death

Ambrisentan 6-min walk distance

6-min walk distance

Riociguat

Indexed pulmonary vascular resistance
Negative on primary outcome, some positive effect on secondary and exploratory end-points

Deleterious effect

Negative

Negative

Negative

Terminated early

Terminated early

Negative

FVC: forced vital capacity; $D\llcorner C 0$ : diffusing capacity of the lung for carbon monoxide. 
This novel tool contributes to the better noninvasive detection of PH in IPF. Unfortunately, the study suffers from limitations, including its retrospective design, and the absence of external validation, although some internal validation was assessed using a bootstrap method. It is debatable whether the proposed score really is easier to perform for the clinician than previous ones $[6,14]$. More importantly, the score was designed to predict a mean PAP $\geqslant 21 \mathrm{mmHg}$, and not a threshold of $\geqslant 25 \mathrm{mmHg}$, which defines $\mathrm{PH}$ as per international guidelines [12]. Although the same group has previously demonstrated that a mean PAP $\geqslant 21 \mathrm{mmHg}$ predicts mortality in patients with IPF [3], the choice of $21 \mathrm{mmHg}$ as a threshold is highly controversial, since it is unlikely that the findings would therefore translate into management decisions. It is unknown whether the finding of a mPAP $>21 \mathrm{mmHg}$ might predict the future development of more severe $\mathrm{PH}$, and, indeed, whether pre-emptive use of $\mathrm{PH}$ therapies may even prevent this. There were very few patients in this cohort with confirmed $\mathrm{PH}$, and especially with severe $\mathrm{PH}$, and the findings may not apply to a population of patients with more advanced IPF and higher prevalence of PH. As the indication to perform RHC was not mentioned in the manuscript, other than being part of their "initial evaluation" protocol, the applicability of the findings based on the study population may be limited.

Although the specificity of the score was relatively good when all three parameters were present, the scoring system had remarkably low sensitivity to detect $\mathrm{PH}$, with a sensitivity varying from $13.2 \%$ to $32.1 \%$ for a score of 0 to 3, challenging the usefulness of the tool to screen for PH. Similarly, the positive predictive value was not more than $65.4 \%$ for a score of 3 , suggesting that in a significant proportion of cases elevated mean PAP would not be confirmed by RHC.

The main limitation of detecting PH in IPF, however, is that so far the approaches taken to tackle vasculopathy in IPF have been deceptive. Indeed, several randomised controlled clinical trials have been conducted to target either the progression of IPF, or haemodynamic or clinical parameters in patients with IPF or IPF-PH, respectively (table 1). Of particular concern, no haemodynamic improvement was found as compared to placebo in subjects with IPF-PH who received a drug approved for pulmonary arterial hypertension; this suggests that $\mathrm{PH}$ drugs might not improve the vasculopathy in IPF, which would explain the absence of clinical improvement. In patients with $\mathrm{PH}$ due to chronic lung diseases, guidelines recommend optimal treatment of the underlying lung disease, including supplemental long-term oxygen therapy [12].

Despite negative results of trials, a glimpse of hope has come from registries demonstrating haemodynamic improvement in a proportion of patients with IPF-PH [19] and possibly survival with sildenafil [20], suggesting that we may not yet have used the right drug in the right target population and with the right study endpoint. Importantly, no trials have been performed in the subgroup of patients with severe $\mathrm{PH}$ associated with IPF or combined pulmonary fibrosis and emphysema, defined by a mean PAP $>35 \mathrm{mmHg}$, or $\geqslant 25 \mathrm{mmHg}$ in the presence of low cardiac output (cardiac index $<2.5 \mathrm{~L} \cdot \mathrm{min}^{-1}$, not explained by other causes) [12]. It remains to be explored whether PH drugs may provide some benefit in subgroups of patients with IPF-PH especially those with the most severe vasculopathy and relatively preserved lung volumes [21]. Furthermore, trials until now have tested various end-points, and it is conceivable that these may not be appropriate. Interestingly, several trials are currently evaluating the potential use of sildenafil as add-on therapy in IPF in addition to available antifibrotic drugs, in patients with probable PH (assessed noninvasively), using pirfenidone (clinicaltrials.gov NCT02951429) or nintedanib (clinicaltrials.gov NCT02802345).

In conclusion, the study by FURUKAWA et al. [18] adds a small stone to building a potential algorithm to detect and possibly manage $\mathrm{PH}$ in IPF. Precapillary $\mathrm{PH}$ is unlikely in patients with a score of 0 , therefore obviating the need to perform a RHC. Precapillary PH has a higher probability to be confirmed at RHC in patients with a score of 3 , but this has limited practical consequences in the absence of therapeutic indication and, especially, absence of demonstrated efficacy of drugs approved to treat pulmonary artery hypertension. Indeed at the threshold of mPAP $>21 \mathrm{mmHg}$, the degree of $\mathrm{PH}$ is likely to reflect the underlying lung disease (including the effect of coexistent emphysema) rather than an independent pulmonary vasculopathy. Prospective studies are still needed to determine the best methods to detect $\mathrm{PH}$ in IPF, and more importantly, to explore whether a selected group of patients with IPF-PH might benefit from the management of $\mathrm{PH}$ with innovative strategies.

\section{References}

1 Harari S, Elia D, Humbert M. Pulmonary hypertension in parenchymal lung diseases: any future for new therapies? Chest 2018; 153: 217-223.

2 Cottin V, Le Pavec J, Prevot G, et al. Pulmonary hypertension in patients with combined pulmonary fibrosis and emphysema syndrome. Eur Respir J 2010; 35: 105-111.

3 Kimura A, Taniguchi H, Kondoh Y, et al. Pulmonary hypertension as a prognostic indicator at initial evaluation in idiopathic pulmonary fibrosis. Respiration 2013; 85: 456-463. 
4 Lettieri CJ, Nathan SD, Barnett SD, et al. Prevalence and outcomes of pulmonary arterial hypertension in advanced idiopathic pulmonary fibrosis. Chest 2006; 129: 746-752.

5 Shorr AF, Wainright JL, Cors CS, et al. Pulmonary hypertension in patients with pulmonary fibrosis awaiting lung transplant. Eur Respir J 2007; 30: 715-721.

6 Zisman DA, Ross DJ, Belperio JA, et al. Prediction of pulmonary hypertension in idiopathic pulmonary fibrosis. Respir Med 2007; 101: 2153-2159.

7 Nathan SD, Shlobin OA, Barnett SD, et al. Right ventricular systolic pressure by echocardiography as a predictor of pulmonary hypertension in idiopathic pulmonary fibrosis. Respir Med 2008; 102: 1305-1310.

8 Nathan SD, Cottin V. Pulmonary hypertension in patients with idiopathic pulmonary fibrosis. In: Hoeper MM, Humbert M, eds. Pulmonary Hypertension (ERS Monograph). Sheffield, European Respiratory Society, 2012; pp. $148-160$.

9 Glaser S, Noga O, Koch B, et al. Impact of pulmonary hypertension on gas exchange and exercise capacity in patients with pulmonary fibrosis. Respir Med 2009; 103: 317-324.

10 Minai OA, Santacruz JF, Alster JM, et al. Impact of pulmonary hemodynamics on 6-min walk test in idiopathic pulmonary fibrosis. Respir Med 2012; 106: 1613-1621.

11 Simonneau G, Gatzoulis MA, Adatia I, et al. Updated clinical classification of pulmonary hypertension. J Am Coll Cardiol 2013; 62: D34-D41.

12 Galie N, Humbert M, Vachiery JL, et al. 2015 ESC/ERS Guidelines for the diagnosis and treatment of pulmonary hypertension. Eur Respir J 2015; 46: 903-975.

13 Arcasoy SM, Christie JD, Ferrari VA, et al. Echocardiographic assessment of pulmonary hypertension in patients with advanced lung disease. Am J Respir Crit Care Med 2003; 167: 735-740.

14 Alkukhun L, Wang XF, Ahmed MK, et al. Non-invasive screening for pulmonary hypertension in idiopathic pulmonary fibrosis. Respir Med 2016; 117: 65-72.

15 Modrykamien AM, Gudavalli R, McCarthy K, et al. Echocardiography, 6-minute walk distance, and distance-saturation product as predictors of pulmonary arterial hypertension in idiopathic pulmonary fibrosis. Respir Care 2010; 55: 584-588.

16 Zisman DA, Karlamangla AS, Kawut SM, et al. Validation of a method to screen for pulmonary hypertension in advanced idiopathic pulmonary fibrosis. Chest 2008; 133: 640-645.

17 Yagi M, Taniguchi H, Kondoh Y, et al. CT-determined pulmonary artery to aorta ratio as a predictor of elevated pulmonary artery pressure and survival in idiopathic pulmonary fibrosis. Respirology 2017; 22: 1393-1399.

18 Furukawa $\mathrm{T}$, Kondoh $\mathrm{Y}$, Taniguchi $\mathrm{H}$, et al. A scoring system to predict the elevation of mean pulmonary arterial pressure in idiopathic pulmonary fibrosis. Eur Respir J 2018; 51: 1701311.

19 Hoeper MM, Behr J, Held M, et al. Pulmonary hypertension in patients with chronic fibrosing idiopathic interstitial pneumonias. PLoS One 2015; 10: e0141911.

20 Rochwerg B, Neupane B, Zhang Y, et al. Treatment of idiopathic pulmonary fibrosis: a network meta-analysis. BMC Med 2016; 14: 18.

21 Cottin V. Treatment of pulmonary hypertension in interstitial lung disease: do not throw out the baby with the bath water. Eur Respir J 2013; 41: 781-783.

22 Zisman DA, Schwarz M, Anstrom KJ, et al. A controlled trial of sildenafil in advanced idiopathic pulmonary fibrosis. N Engl J Med 2010; 363: 620-628.

23 Raghu G, Behr JB, Brown KK, et al. ARTEMIS-IPF: a placebo-controlled trial of ambrisentan in idiopathic pulmonary fibrosis. Am J Respir Crit Care Med 2012; 185: A3632f.

24 King TE Jr, Behr J, Brown KK, et al. BUILD-1: a randomized placebo-controlled trial of bosentan in idiopathic pulmonary fibrosis. Am J Respir Crit Care Med 2008; 177: 75-81.

25 King TE Jr, Brown KK, Raghu G, et al. BUILD-3: a randomized, controlled trial of bosentan in idiopathic pulmonary fibrosis. Am J Respir Crit Care Med 2011; 184: 92-99.

26 Raghu G, Million-Rousseau R, Morganti A, et al. Macitentan for the treatment of idiopathic pulmonary fibrosis: the randomised controlled MUSIC trial. Eur Respir J 2013; 42: 1622-1632.

27 Nathan SD, Behr J, Cottin V, et al. Idiopathic interstitial pneumonia-associated pulmonary hypertension: A target for therapy? Respir Med 2017; 122: Suppl. 1, S10-SS3.

28 Corte TJ, Keir GJ, Dimopoulos K, et al. Bosentan in pulmonary hypertension associated with fibrotic idiopathic interstitial pneumonia. Am J Respir Crit Care Med 2014; 190: 208-217. 